www.jmscr.igmpublication.org

Impact Factor (SJIF): 6.379

Index Copernicus Value: 71.58

ISSN (e)-2347-176x ISSN (p) 2455-0450

crossrefDOI: https://dx.doi.org/10.18535/jmscr/v6i7.59

Journal Of Medical Science And Clinical Research

\title{
Assessment of Family Physician's Knowledge, Attitude and Barriers to the use of Oral Anticoagulation Therapy among Atrial Fibrillation Patients in Riyadh City
}

\author{
Authors \\ Dr Amani Alshammari, Dr Mashhor Alhantoushi \\ $\mathrm{PMSH}$
}

\begin{abstract}
Background: Atrial fibrillation $(A F)$ is the most common arrhythmia type. The prevalence of $A F$ is associated with different factors such as age, body mass index (BMI), physical activity, genetic factors and lifestyle factors. AF is associated with an increased risk of stroke and embolic events. Treatment guidelines recommend the combination of anticoagulant and rate control with rhythm control for highly symptomatic patients.
\end{abstract}

Aim: To evaluate the knowledge, attitude, and barriers of family physicians to use oral anticoagulation in arterial fibrillation.

Methods: This study is a cross sectional study which was conducted in 4 hospitals and 8 primary care centers at Riyadh, Saudi Arabia, on family physicians. The study used pre-designed questionnaire which involved questions about demographics, knowledge, attitude and barriers.

Results: There were 52 physicians had average awareness about practice guidelines, 27 had good awareness, 4 had excellent awareness, 17 and 14 had fair and poor awareness respectively. The overall knowledge was significantly associated with job position, where consultants had higher mean knowledge. The most common barriers were lack of follow-up system and lab investigations.

Conclusion: There was positive attitude with moderate overall knowledge, it is recommended to increase knowledge by establishing educational program and it is necessary to provide follow-up system and facilitate performing of lab investigations to decrease parries and facilitate practice of use of anticoagulants.

Keywords: AF, Oral anticoagulants, Family physicians, knowledge of anticoagulants, attitude of anticoagulants, anticoagulants barriers.

\section{Introduction}

The most common arrhythmia encountered type is atrial fibrillation $(\mathrm{AF})^{[1]}$, in 2010 , the global prevalence of AF was 33.5 million, 20.9 of them were males and 12.6 were females ${ }^{[2]}$. The prevalence of $\mathrm{AF}$ was reported to be $14.7 \%$ in Saudi adults with chronic heart failure in Qassim region $^{[3]}$. The prevalence of $\mathrm{AF}$ is associated with age, where it increase with age as the prevalence was $0.5 \%$ in those patients with age $<40$ years, whereas it was prevalent in $5 \%$ of patients aged $>65$ years $^{[4]}$ the prevalence of AF is increasing due to population aging ${ }^{[5]}$. There are several risk factors for AF including BMI, physical activity, 
genetic factors and lifestyle factors such as smoking and alcohol consumption ${ }^{[4]}$. AF is associated with an increased risk of embolic events, stroke ${ }^{[6]}$, ischemic heart disease and valvular diseases ${ }^{[7]}$. 20-30 \% of patients who suffer stroke have $\mathrm{AF}^{[8]}$. The $\mathrm{AF}$ patients who are under the risk of stroke include individuals with age older than 65 years and those with history of diabetes, hypertension, prior transient ischemic attack or strok ${ }^{[9]}$ heart failure, arteriopathy and female $\operatorname{sex}^{[5]}$. AF is associated with an increasing procoagulant in the blood ${ }^{[10]}$, so it is possible to form thrombi in the left atrium in case of absence of regular effective mechanical contractions ${ }^{[11]}$. The management of AF involves two strategies; rhythm and rate control, which can be achieved pharmacologically and non-pharmacologically ${ }^{[7]}$. Treatment guidelines recommend anticoagulant and rate control with combination of rhythm control for highly symptomatic patients ${ }^{[12,13]}$. AF management often depends on the administration of anticoagulant therapy ${ }^{[14]}$. Vitamin $\mathrm{K}$ antagonists oral anticoagulants significantly decrease the risk of stroke in AF patients ${ }^{[15,16]}$. The use of these oral anticoagulants is complex as they require continuous monitoring for the international normalised ratio (INR) in order to make the patient at optimum protection against thrombosis with avoiding the risk of haemorrhage ${ }^{[17,18]}$, these medications also show drug and food interactions ${ }^{[5]}$. The novel oral anticoagulants (NOACs) are new oral anticoagulants which make the AF patients show lower risk of stroke, hemorrhage and death but with higher risk of gastrointestinal bleeding ${ }^{[19]}$, however there are no drug or food interactions of these anticoagulants [5]. Several clinical trials have investigated the prevention of stroke in patients with AF by using anticoagulant such as warfarin and with or without $\operatorname{aspirin}^{[20-23]}$. The use of aspirin has resulted in a significant effect with lower risk reduction (36\%) as reported by study of five randomized controlled trials in $1994^{[9]}$. In another randomized controlled trials, it was shown that the combination of aspirin and low-dose oral anticoagulation $(\mathrm{INR}<1.5)$ showed additive little protection against stroke than aspirin alone in patients with $\mathrm{AF}^{[24]}$. The combination of higher intensity oral anticoagulant with aspirin may increase the risk of intracranial hemorrhage, especially in elderly patients ${ }^{[25]}$. It was found that the risk of stroke resulting from AF can be reduced by warfarin treatment from 4.5 to $1.45 \%$ per year ${ }^{[20-23]}$. There are several barriers for the use of anticoagulants related to physicians including facing difficulty in keeping patients within the therapy range and some physicians are aware of clinical practice guidelines, however these guidelines can't be applied to their patients [1]. Another barrier is the fear of physicians to prescribe anticoagulants for advanced age patients, in one systematic review it was reported that physicians were against prescribing anticoagulants to elderly patients especially those older than 80 years ${ }^{[26]}$. Also concerning about falls risk and bleeding risk of patients was another barrier ${ }^{[14]}$. In cross sectional survey ${ }^{[14]}$ several barriers were reported to treatment with warfarin including advanced age, poor patient compliance, monitoring issues. these barriers has affected physicians in decision making. It is very important to empower the knowledge of physicians`s about anticoagulants to improve using of anticoagulants for $\mathrm{AF}$ patients as new anticoagulant medication are available ${ }^{[11]}$. Anderson et al $2007^{[27]}$ have found that physicians rarely chose anti-coagulants for AF patients and the knowledge of doctors about stroke and bleeding differs. The use of anticoagulant is underused with broad variety in clinical practice. Research demonstrates that numerous patients who should receive anticoagulants, don't receive them, with misperception of the dangers and advantages associated with oral anticoagulation. There was no previous study included knowledge, attitude and barriers in gulf countries and as far as we know there was no study in Saudi Arabia investigated the knowledge, attitude and barriers of family physicians to use oral anticoagulants for $\mathrm{AF}$ patients, so we conducted this study to assess knowledge, attitude and barriers of family 
physicians to use oral anticoagulants therapy for AF patients. This study will be useful to enhance attitudes of physicians about decision making in atrial fibrillation and the use of oral anticoagulation, also it will help to recognize the practice patterns of the physicians to use oral anticoagulation for stroke prevention in atrial fibrillation.

\section{Subjects and Method}

\section{Subjects and Study Design}

This study is a cross-sectional study which was conducted in the period from November 2017 to January 2018. The study has included 114 family physicians who are working in 4 hospitals and 8 primary care centers at Riyadh, Saudi Arabia, the study included residents, registrars, and consultants. sample size was calculated by MINITAB 15 .This study was approved by the responsible management to be conducted on participants in 8 centers only of health ministry. The study used pre-designed questionnaire which involved questions about demographics and ten questions to assess the knowledge and attitude and 1 question to investigate the barriers toward the use of an anticoagulant. Informed consent was obtained from all participants and data were used with high confidentiality. A pilot study was performed including 28 physicians from the two different places.

\section{Statistical analysis}

Data were analyzed using SPSS software version 16, chi-square was used as a test of significance to compare qualitative variables between different groups, with P-value significant level of less than 0.05

\section{Results}

In the present study, there were 18 consultants, 11 senior specialists, 31 specialists and 54 residents. There were 30 physicians had less than five years of experience after residency, 26 physicians had 59 years, and 20 physicians had ten years and more of experience. Females were more dominant (62) than males (52). In this study there were 2 questions to investigate attitude; the first question was to investigate the practice of physicians to the guidelines in managing $\mathrm{AF}$ with oral anticoagulants, the large majority of physicians (52\%) had average awareness, followed by those who had good awareness (27) then fair and poor awareness $(17 \& 14)$ respectively and there was 4 only had excellent awareness, table1.

Table1: Correlation of different variables and the awareness of practice guidelines

\begin{tabular}{|c|c|c|c|c|c|c|}
\hline Factor & $\begin{array}{r}\text { Poor } \\
\text { (14) }\end{array}$ & $\begin{array}{l}\text { Fair } \\
(17)\end{array}$ & Average (52) & $\begin{array}{c}\text { Good } \\
(27)\end{array}$ & Excellent (4) & P-value \\
\hline $\begin{array}{l}\text { job title } \\
\text { Consultant }\end{array}$ & $2(11.1 \%)$ & $2(11.1 \%)$ & $6(33.3 \%)$ & $6(33.3 \%)$ & $2(11.1 \%)$ & \multirow{4}{*}{0.194} \\
\hline Senior specialist & $0(0 \%)$ & $4(36.4 \%)$ & $4(36.4 \%)$ & $2(18.2 \%)$ & $1(9.1 \%)$ & \\
\hline Specialist & $3(9.7 \%)$ & $2(6.5 \%)$ & $17(54.8 \%)$ & $8(25.8 \%)$ & $1(3.2 \%)$ & \\
\hline Resident & $9(16.7 \%)$ & $9(16.7 \%)$ & $25(46.3 \%)$ & $11(20.4 \%)$ & $0(0 \%)$ & \\
\hline $\begin{array}{l}\text { Gender Type } \\
\text { Male }\end{array}$ & $4(7.7 \%)$ & $6(11.5 \%)$ & $27(51.9 \%)$ & $13(25 \%)$ & $2(3.8 \%)$ & \multirow[t]{5}{*}{0.508} \\
\hline Female & $10(16.1 \%)$ & $11(17.7 \%)$ & $25(40.3 \%)$ & $14(22.6 \%)$ & $2(3.2 \%)$ & \\
\hline $\begin{array}{l}\text { Years of experience after } \\
\text { residency program } \\
<5 \text { years }\end{array}$ & $4(13.3 \%)$ & $6(20 \%)$ & $11(36.7 \%)$ & $8(26.7 \%)$ & $1(3.3 \%)$ & \\
\hline \multirow[t]{2}{*}{$5-9$ years } & $2(7.7 \%)$ & $4(15.4 \%)$ & $11(42.3 \%)$ & $8(30.8 \%)$ & $1(3.8 \%)$ & \\
\hline & $1(5 \%)$ & $2(10 \%)$ & $9(45 \%)$ & $6(30 \%)$ & $2(10 \%)$ & \\
\hline
\end{tabular}




\begin{tabular}{|c|c|c|c|c|c|c|}
\hline 10-0r more & & & & & & \multirow[b]{3}{*}{0.453} \\
\hline not applicable & $7(0 \%)$ & $4(11.8 \%)$ & $18(52.9 \%)$ & $5(14.7 \%)$ & $0(0 \%)$ & \\
\hline $\begin{array}{l}\text { Prescribing oral } \\
\text { anticoagulant for treatment } \\
\text { of AF in last } 6 \text { month } \\
\text { Yes }\end{array}$ & $0(0 \%)$ & $0(0 \%)$ & $4(57.1 \%)$ & $3(42.9 \%)$ & $0(0 \%)$ & \\
\hline No & $14(13.1 \%)$ & $17(15.9 \%)$ & $48(44.9 \%)$ & $24(22.4 \%)$ & $4(3.7 \%)$ & \\
\hline $\begin{array}{l}\text { Attending training or } \\
\text { workshop on anticoagulation } \\
\text { therapy in last } 6 \text { month } \\
\text { Yes }\end{array}$ & $0(0 \%)$ & $2(16.7 \%)$ & $5(41.7 \%)$ & $5(41.7 \%)$ & $0(0 \%)$ & 0.403 \\
\hline No & $14(13.7 \%)$ & $15(14.7 \%)$ & $47(46.1 \%)$ & $22(21.6 \%)$ & $4(3.9 \%)$ & \\
\hline $\begin{array}{l}\text { type of working setting } \\
\text { Hospital-based family medicine }\end{array}$ & $5(8.9 \%)$ & $11(19.6 \%)$ & $27(48.2 \%)$ & $13(23.2 \%)$ & $0(0 \%)$ & \\
\hline $\begin{array}{l}\text { community based family } \\
\text { primary }\end{array}$ & $8(14 \%)$ & $6(10.5 \%)$ & $25(43.9 \%)$ & $14(24.6 \%)$ & $4(7 \%)$ & \\
\hline
\end{tabular}

Table2: Correlation between different variables and attitude of physicians

\begin{tabular}{|c|c|c|}
\hline Variables & $\begin{array}{l}\text { Awareness of the current practice } \\
\text { guidelines in managing AF with } \\
\text { oral anticoagulant } \\
(\text { Mean } \pm \text { SD) }\end{array}$ & $\begin{array}{l}\text { AF is not a disease of family } \\
\text { medicine scope } \\
(\text { Mean } \pm \text { SD })\end{array}$ \\
\hline $\begin{array}{l}\text { Job title } \\
\text { Consultant } \\
\text { Senior specialist } \\
\text { Specialist } \\
\text { Resident } \\
\text { P-value }\end{array}$ & $\begin{array}{c}3.22 \pm 1.16 \\
3.00 \pm 1.00 \\
3.06 \pm 0.92 \\
2.70 \pm 0.98 \\
0.18\end{array}$ & $\begin{array}{c}2.33 \pm 076 \\
2.27 \pm 0.78 \\
2.67 \pm 1.10 \\
3.00 \pm 1.18 \\
0.05\end{array}$ \\
\hline $\begin{array}{l}\text { Gender } \\
\text { Male } \\
\text { Female } \\
\text { P-value }\end{array}$ & $\begin{array}{c}3.05 \pm 0.91 \\
2.79 \pm 1.07 \\
0.16\end{array}$ & $\begin{array}{c}2.44 \pm 1.03 \\
2.98 \pm 1.09 \\
0.00\end{array}$ \\
\hline $\begin{array}{l}\text { Years of experience after residency program } \\
<5 \text { years } \\
5-9 \text { years } \\
10 \text { and more } \\
\text { Not applicable } \\
\text { P-value }\end{array}$ & $\begin{array}{c}2.86 \pm 1.07 \\
3.07 \pm 0.97 \\
3.30 \pm 0.97 \\
2.61 \pm 0.98 \\
0.91\end{array}$ & $\begin{array}{l}2.40 \pm 1.07 \\
2.38 \pm 0.89 \\
2.60 \pm 0.88 \\
3.26 \pm 1.10 \\
0.002\end{array}$ \\
\hline $\begin{array}{l}\text { Prescribing oral anticoagulant for treatment of } \\
\text { AF in last } 6 \text { month } \\
\text { Yes } \\
\text { No } \\
\text { P-value }\end{array}$ & $\begin{array}{c}3.42 \pm 0.53 \\
2.87 \pm 1.02 \\
0.16\end{array}$ & $\begin{array}{c}2.42 \pm 0.53 \\
2.75 \pm 1.12 \\
0.44\end{array}$ \\
\hline $\begin{array}{l}\text { Attending training or workshop on } \\
\text { anticoagulation therapy in last } 6 \text { month } \\
\text { Yes } \\
\text { No } \\
\text { P-value }\end{array}$ & $\begin{array}{c}3.25 \pm 0.75 \\
2.87 \pm 1.03 \\
0.22\end{array}$ & $\begin{array}{c}2.83 \pm 0.93 \\
2.72 \pm 1.11 \\
0.75\end{array}$ \\
\hline $\begin{array}{l}\text { Type of working setting } \\
\text { Hospital-based family medicine } \\
\text { Community based family primary } \\
\text { P-value }\end{array}$ & $\begin{array}{c}2.85 \pm 0.88 \\
3.00 \pm 1.10 \\
0.44\end{array}$ & $\begin{array}{c}2.69 \pm 0.98 \\
2.73 \pm 1.17 \\
0.84\end{array}$ \\
\hline
\end{tabular}

The mean physicians' attitude was assessed shown in table 2. The mean score of awareness of regarding characteristics of participants and it is the practice guidelines and opinion of physicians 


\section{JMSCR Vol||06||Issue||07||Page 348-357||July}

if $\mathrm{AF}$ was a disease of family medicine scope wasn't differ regarding job position, prescribing oral anticoagulants, attending training on anticoagulants and type of work setting of physicians. Gender and years of experience were significantly affecting the mean score of physicians' opinion if AF is a disease of family medicine scope (P-value $=0.00,0.00$ for each gender and years of experience), while no significant effect of gender or years of experience found on awareness of practice guidelines, table( $1,2)$.

Table 3: Correlation between different variables and knowledge of physicians

\begin{tabular}{|l|c|}
\hline Variables & $\begin{array}{c}\text { Knowledge } \\
\text { (Mean } \pm \text { SD) }\end{array}$ \\
\hline Job title & \\
Consultant & $2.44 \pm 1.54$ \\
Senior specialist & $1.63 \pm 1.28$ \\
Specialist & $1.12 \pm 1.05$ \\
Resident & $1.35 \pm 1.03$ \\
P-value & 0.00 \\
\hline Gender & \\
Male & $1.59 \pm 1.33$ \\
Female & $1.40 \pm 1.12$ \\
P-value & 0.40 \\
\hline Years of experience & \\
$<5$ years & $1.33 \pm 1.02$ \\
5-9 years & $1.76 \pm 1.42$ \\
10 and more & $1.75 \pm 1.51$ \\
Not applicable & $1.35 \pm 1.04$ \\
P-value & 0.38 \\
\hline Prescribing oral anticoagulant for treatment of AF & \\
in last 6 month & $1.00 \pm 1.41$ \\
Yes & $1.52 \pm 1.20$ \\
No & 0.27 \\
P-value & \\
\hline Attending training or workshop on anticoagulation & \\
therapy in last 6 month & $1.50 \pm 156$ \\
Yes & $1.49 \pm 1.18$ \\
No & 0.97 \\
P-value & \\
\hline Type of working setting & $1.58 \pm 1.3$ \\
Hospital-based family medicine & 0.38 \\
Community based family primary & \\
P-value & \\
\hline
\end{tabular}

The second part of the questionnaire was to assess the knowledge of physicians which included 5 questions, the overall score of knowledge was significantly ( $\mathrm{P}$-value $=0.00)$ higher in consultants, where the mean $\pm \mathrm{SD}$ score of knowledge was
2.44 \pm 1.54 , while gender, years of experience, prescribing oral anticoagulants, attending training on anticoagulants and type of work setting of physicians was not affecting the mean score of knowledge of physicians, table 3. 
Table 4 (most common barriers for each variable)

\begin{tabular}{|c|c|}
\hline Variable & The most common barrier \\
\hline consultants & lack of follow-up system $(55.6 \%)$ \\
\hline senior specialists, & AF patients non attending family medicine $(40 \%)$, \\
\hline specialists & lack of lab investigations $(53.3 \%)$ \\
\hline residents & limited knowledge and experience $(50 \%)$. \\
\hline male & lack in lab investigations $(43.1 \%)$ \\
\hline female & $\begin{array}{l}\text { limited knowledge and experience }(47.5 \%) \text { and lack of } \\
\text { follow-up system }(47.5 \%)\end{array}$ \\
\hline physicians of $<5$ years & Lack of follow-up system was the major barriers $(48.3 \%)$ \\
\hline $5-9$ years of experience & Lack of follow-up system was the major barriers (44\%) \\
\hline$\geq 10$ years of experience & lack of lab investigation $(80 \%)$. \\
\hline $\begin{array}{l}\text { physicians who prescribed anticoagulants } \\
\text { for treatment of AF in the previous } 6 \\
\text { month }\end{array}$ & Lack of lab investigations $(57.1 \%)$ \\
\hline $\begin{array}{l}\text { physicians who did not prescribe } \\
\text { anticoagulants for treatment of AF in the } \\
\text { previous } 6 \text { month }\end{array}$ & lack of follow-up systems ( $47 \%)$ \\
\hline $\begin{array}{l}\text { Physicians who attended training on } \\
\text { anticoagulant therapy }\end{array}$ & lack of follow-up system (41.7\%) \\
\hline $\begin{array}{l}\text { Physicians who did not attend training on } \\
\text { anticoagulant therapy }\end{array}$ & limited knowledge and experience $(46 \%)$. \\
\hline Hospital-based family medicine & limited knowledge and experience $(56.4 \%)$ \\
\hline community-based family medicine & lack of lab investigations $(69.6 \%)$. \\
\hline
\end{tabular}

The mean score of each question of knowledge part was correlated with characteristics of participants. Regarding job position, consultants answered correctly the time to investigate INR in warfarin-treated patients $(\mathrm{P}$-value $=0.00)$ and both senior specialists and specialists answered correctly the advantage of novel oral anticoagulants $(\mathrm{P}$-value $=0.00)$. Physicians with 59 years of experience answered correctly the time to investigate INR in warfarin-treated patients ( $\mathrm{P}$ value $=0.00$ ), while those with experience of 10 years and more answered correctly the advantage of novel oral anticoagulants (P-value=0.04). The question about the cutoff value for CHA2DS2VASc score was answered correctly by hospitalbased family medicine physicians (P-value $=0.01$ ). Regarding other questions there were no significant differences between physicians with regard to different characteristics.
Barriers to the use of oral anticoagulation therapy were assessed according to demographics of participants. Lack of follow-up system as well as lab investigations were the most common barriers reported.

The most common barriers for each variable shown in table 4 .

\section{Discussion}

The present study is the first study to assess physicians' knowledge, attitude and barriers of using anticoagulant for AF patients in Saudi Arabia. There was no previous similar study, so we couldn't find any previous findings to compare with. Assessing attitude of physicians involved the investigation of the awareness of practice guidelines in managing $\mathrm{AF}$ with oral anticoagulants and investigating if they were agree that AF wasn't a disease of family medicine 
scope. The large majority of physicians reported average awareness (52), while 27 reported good awareness and only 4 reported excellent awareness, while 14 and 17 reported poor and fair awareness respectively. This indicates a positive attitude of family physicians, average, good and excellent awareness collectively referred to positive attitude, whereas poor and fair awareness referred to negative attitude; 83 vs 31 for positive and negative attitude respectively. Attitude of physicians was not affected by any of physicians' characteristics, the job position, years of experience, gender, prescription of oral anticoagulants, attendance of training about anticoagulants and type of work settings had no significant effect on the attitude of family physicians. However the attitude of physicians was significantly affected by gender and years of experience when investigating if $\mathrm{AF}$ was a disease of family medicine scope. The overall knowledge of participants was significantly associated with job position (P-value=0.00), where consultants had the highest knowledge among other physicians, which could be attributed to their long experience compared to others, dealing with more patients, and having more exposure to source of knowledge, all these factors played a critical role in increasing the knowledge of consultants. There were no significant difference in the level of knowledge regarding gender and years of experience, prescribing anticoagulants, attending training on anticoagulants and type of work settings. Each question in knowledge part was correlated with characteristics of physicians, consultants answered correctly the time for INR to be performed in warfarin treated patients, while both senior specialist and residents answered correctly the advantage of novel oral anticoagulants compared to warfarin as they reported that novel oral anticoagulants can be given to end-stage renal disease patients. The previous two questions were significantly affected by the job position, while there was no significant difference between knowledge about other questions regarding job position. The same was found regarding experience years, the knowledge of correct answers of the previous two questions were significantly associated with experience years, physicians with experience of 5-9 years knew the correct answer about the time to perform INR for warfarin-treated patients, while those with 10 years and more knew the correct answer about the advantage of novel oral anticoagulants. Gender and prescribing anticoagulants and training on anticoagulants had no influence on the answers of physicians. Being hospital-based family medicine physicians, this group have answered correctly the cutoff value of CHA2DS2VASc score for strong recommendation for oral anticoagulation, however no other significances found. The most common barriers reported by participants were lack of follow-up system, followed by lack of lab investigations and limited knowledge. Residents and physicians who didn't attend training reported limited knowledge and experience and this reflects the importance of the training programs and workshops. The availability of supportive services as follow-up systems and lab investigations are important factor to encourage family physicians to see more $\mathrm{AF}$ patients especially in primary health care settings (community-based family medicine).

This study has many limitations including; The formulation of unprecedented questionnaire, the sample size was small and we couldn't find any previous study to compare our findings with, so further studies with large sample size are very recommended.

\section{Conclusion}

There was positive attitude of physicians about oral anticoagulants for AF patients and good awareness toward AF management. The physician`s attitude was affected by many different factors. Overall, knowledge was moderate, higher in consultants.

Lack of follow- up system as well as lab investigation were the most common barriers reported. 


\section{Recommendations}

It is recommended to increase knowledge by establishing educational program and it is necessary to provide follow-up system and facilitate performing of lab investigations to decrease parries and facilitate practice of use of anti-coagulants.

\section{References}

1. Greenlee RT and Vidaillet H. Recent progress in the epidemiology of atrial fibrillation. Curr Opin Cardiol. 2005; 20(1):7-14.

2. Chugh SS, Havmoeller R, Narayanan K, Singh D, Rienstra M, Benjamin EJ, et al. Worldwide epidemiology of atrial fibrillation: a Global Burden of Disease 2010 Study. Circulation. 2014;129(8): 837-47.

3. Al-Harbi and Al-Suhaibani M. The prevalence of atrial fibrillation among adult Saudi patients with chronic heart failure at Prince Sultan Cardiac Center, Qassim (2011-2014). Hamdan Medical Journal 2015; 8(Suppl. 1):201-202.

4. Sankaranarayanan R, Kirkwood G, Dibb K and Garratt CJ. Comparison of Atrial Fibrillation in the Young versus That in the Elderly: A Review. Cardiology Research and Practice;2013.

5. Dalmau GM, Arderiu ES, Montes MBE, SolàI, Saco SP and Coello PA. Patients'and physicians'perceptions and attitudes about oral anticoagulation and atrial fibrillation: a qualitative systematic review. BMC Family Practice; 2017:18:3.

6. Wolf PA, Abbott RD and Kannel WB. Atrial fibrillation as an independent risk factor for stroke: The Framingham Study. Stroke 1991; 22:983-988.

7. Hersi A, Abdul-Moneim M, Almous'ad A, Al-Samadi F, AlFagih A and Sweidan R. Saudi Atrial Fibrillation Survey: National, Observational, Cross-sectional Survey Evaluating Atrial Fibrillation Management and the Cardiovascular Risk Profile of Patients With Atrial Fibrillation. Angiology; 2015: 66(3) 244-248.

8. Patel MR, Mahaffey KW, Garg J, et al. Rivaroxaban versus warfarin in nonvalvular atrial fibrillation. $\mathrm{N}$ Engl $\mathrm{J}$ Med; 2011:365:883-91.

9. The Atrial Fibrillation Investigators: Risk factors for stroke and efficacy of antithrombotic therapy in atrial fibrillation. Analysis of pooled data from five randomized controlled trials. Arch Intern Med1994;154:1449-1457.

10. Gustafsson C, Blomback M, Britton M, Hamsten A and Svensson J. Coagulation factors and the increased risk of stroke in nonvalvular atrial fibrillation. Stroke 1990;21:47-51.

11. Buckingham TA and Hatala R. Anticoagulants for Atrial Fibrillation: Why Is the Treatment Rate So Low?. Clin. Cardiol; 2002:25:447-454

12. Fuster V, Ryden LE, Caimom DS, et al. ACC/AHA/ESC 2006. Guidelines for the management of patients with atrial fibrillation. A report of the American college of cardiology/American heart association task force on practice guidelines and the European society of cardiology committee for practice guidelines: developed in collaboration with the European heart rhythm association and the heart rhythm society. Circulation. 2006;114(7):257-354.

13. Snow V, Weiss KB, Le Fevre $M$, et al. Management of newly detected atrial fibrillation: a clinical practice guideline from the American academy of family physicians and the American college of physicians. Ann Intern Med; 2003:139(12):1009-1017.

14. Nicholls SG, Brehaut JC, Arim RG, Carroll K, Perez R, Shojania KG et al. Impact of stated barriers on proposed warfarin prescription for atrial fibrillation: 
a survey of Canadian physicians. Thrombosis Journal; 2014:12:13.

15. Boysen G, Connolly S, Esekowitz M, Hart R, James K, Kistler P, et al. Risk Factors for Stroke and Efficacy of Antithrombotic Therapy in Atrial Fibrillation Analysis of Pooled Data From Five Randomized Controlled Trials. Arch Intern Med; 1994:154(13):1449-57.

16. Hart RG, Pearce LA andAguilar MI. Metaanalysis: antithrombotic therapy to prevent stroke in patients who have nonvalvular atrial fibrillation. Ann Intern Med. 2007;146(12):857-67.

17. Kirchhof P, Benussi S, Kotecha D, Ahlsson A, Atar D, Casadei B, et al; Authors/Task Force Members; Document Reviewers. 2016 ESC Guidelines for the management of atrial fibrillation developed in collaboration with EACTS: The Task Force for the management of atrial fibrillation of the European Society of Cardiology (ESC)Developed with thespecial contribution of the European Heart Rhythm Association (EHRA) of the ESCEndorsed by the European Stroke Organisation (ESO). Eur Heart J. 2016 Aug 27.

18. January CT, Wann LS, Alpert JS, Calkins $\mathrm{H}$, Cigarroa JE, Cleveland Jr JC, et al, ACC/AHA Task Force Members. 2014 AHA/ ACC/HRS guideline for the management of patients with atrial fibrillation: executive summary: a report of the American College of Cardiology/ American Heart Association Task Force on practice guidelines and the Heart Rhythm Society. Circulation. 2014;130(23):2071-104.

19. Ruff CT, Giugliano RP, Braunwald E, Hoffman EB, Deenadayalu N, Ezekowitz $\mathrm{MD}$, et al. Comparison of the efficacy and safety of new oral anticoagulants with warfarin in patients with atrial fibrillation: a meta-analysis of randomised trials. Lancet; 2014;383(9921):955-62.

20. Connolly SJ, Laupacis A, Gent M, Roberts RS, Cairns JA and Joyner C.Canadian Atrial Fibrillation Anticoagulation (CAFA) Study. J Am Coll Cardiol 1991;18:349-355.

21. Ezekowitz MD, Bridgers SL, James KE, Carliner NH, Colling CL, Gornick CC, et al, for the Veterans Affairs Stroke Prevention in Nonrheumatic Atrial Fibrillation Investigators. Warfarin in the prevention of stroke associated with nonrheumatic atrial fibrillation. $\mathrm{N}$ Engl J Med1992;327:1406-1412.

22. The Boston Area Anticoagulation Trial for Atrial Fibrillation Investigators: The effect of low-dose warfarin on the risk of stroke in patients with nonrheumatic atrial fibrillation. N Engl J Med; 1990:323:1505-1511

23. Stroke Prevention in Atrial Fibrillation Study. Final results. Circulation 1991;84:527-539.

24. Stroke Prevention in Atrial Fibrillation III randomised clinical trial: Adjusted-dose warfarin versus low-intensity, fixed-dose warfarin plus aspirin for high-risk patients with atrial fibrillation. Lancet; 1996;348:633-638

25. Hart RG, Benavente $O$ and Pearce LA. Increased risk of intracranial hemorrhage when aspirin is combined with warfarin: A meta-analysis and hypothesis. Cerebrovasc Dis 1999;9:215-217

26. Pugh D, Mead GE. Attitudes of physicians regarding anticoagulation for atrial fibrillation: a systematic review. Age Ageing 2011; 40: 675-83.

27. Anderson N, Fuller R and Dudley N. 'Rules of thumb'or reflective practice? Understanding senior physicians'decisionmaking about anti-thrombotic usage in atrial fibrillation. Q J Med 2007; 100:263269. 
28. Therapeutic Guidelines Cardiovascular Writing Group. Therapeutic Guidelines: Cardiovascular, 3rd edition. Melbourne: Therapeutic Guidelines Limited; 1999.

29. Kilborn M. Atrial fibrillation. Med J Aust 1999; 170: 498-504.

30. Thomas J. Australian Prescriptions Products Guide, 28th edn. Melbourne: Australian Pharmaceutical Publishing Company Limited; 1999.

31. PETERSON GM, Boom K, Jackson SL and Vial JH. Doctors'beliefs on the use of antithrombotic therapy in atrial fibrillation: identifying barriers to stroke prevention. Internal Medicine Journal 2002; 32: 1523.

32. Monette J, Gurwitz JH, Rochon PA, Avorn J. Physician attitudes concerning warfarin for stroke prevention in atrial fibrillation: results of a survey of long-term care practitioners. J Am Geriatr Soc 1997; 45: 1060-5.

33. Gross CP, Vogel EW, Dhond AJ, Marple CB, Edwards RA, Hauch O, et al. Factors Influencing Physicians'Reported Use of Anticoagulation Therapy in Nonvalvular Atrial Fibrillation: A Cross-Sectional Survey. Clinical Therapeutics; 2003:25(6): 1750-1764.

34. Lee VWY, Tam CS, Yan BP, Yu CM, Lam YY. Barriers to Warfarin Use for Stroke Preventionin Patients With Atrial Fibrillation in Hong Kong. Clin. Cardiol; 2013:36, 3, 166-171. 